\title{
Current issues in the management of children with acute lymphocytic leukaemia
}

\author{
Donald Pinkel
}

Department of Pediatrics, Temple University School of Medicine, Philadelphia, Pennsylvania and St Christopher's Hospital for Children. Philadelphia, Pennsylvania, USA.

\section{Introduction}

In the 12 years since curative therapy for acute lymphocytic leukaemia (ALL) became accepted, the lecterns and literature have reflected considerable concern and activity toward establishing optimal methods. Many issues have been raised about classification and prognostic stratification, drug selection, drug combination and dosage, duration of therapy, prevention of meningeal and testicular relapse, infection control, psychosocial support and sequelae of treatment. In addition, the use of alternate methods such as immunotherapy and bone marrow transplantation have been explored.

The purpose of this paper is to describe some of these issues and to present some thoughts about them.

\section{The goal of management}

Although palliation was once the goal of leukaemia therapy, most haematologists and cancer therapists have come to accept cure as a reasonable expectation for children with ALL. This means that the criterion for success is continuous leukaemia-free survival, off all therapy, and at little or no risk of relapse. For the majority of children with ALL, this point appears approximately 7 years after diagnosis and 4 years after cessation of treatment (George et al., 1979). Treatment regimens, therefore, need to be evaluated and compared in terms of 7 year cure rates. The custom of utilizing complete remission durations, persisting from the pre-curative era, can be discontinued.

The importance of curative therapy is directly proportional to its availability and accessibility for everyone who needs it. For children, who have no control over their socioeconomic status and residence, it is mandatory that there be no barriers to their

Donald Pinkel, M.D.

Correspondence: Department of Pediatrics, Temple University School of Medicine, 2600 N. Lawrence Street, Philadelphia, PA 19133 USA.

curative treatment. How can this be accomplished? As physicians and scientists we can only suggest that political leaders place highest priority on child health. including facilities for curative leukaemia therapy. However, we have the power within our own ranks to insist that therapeutic research be directed toward simplification, reduced technology and less cost so that ready availability and accessibility of curative therapy will be more feasible.

\section{Classification and prognostic stratification}

Biological species of ALL can be identified using a combination of morphological, cytochemical, immunological, genetic and clinical criteria. Not every strain of ALL within a species will demonstrate all criteria. As with enteric bacteria, some strains do not clearly fall into one species or the other. However, for purposes of investigation and management, the determination of biological species appears to be as important to leukaemia therapy as to antibacterial therapy.

Children's ALL can be divided into that of Blymphocyte lineage and that of T-lymphocyte derivation (Table I). The most frequent B-lymphocyte species is common ALL (Bowman et al., 1981a; Pullen et al., 1981; Greaves et al., 1981; Greaves et al., 1983).

Table I Biological species of acute lymphocytic leukaemia in children

\begin{tabular}{lc}
\hline Species & $\%$ of patients* \\
\hline B-lymphocyte series & 60 \\
Common & 15 \\
Pre-B & 10 \\
Null & 1 \\
B-lymphoblastic & 14 \\
T-lymphocyte series &
\end{tabular}

* Approximate \% (Greaves et al., 1981; Pullen et al., 1981; Bowman et al., 1981a).

C The Fellowship of Postgraduate Medicine, 1985 
This occurs most often in white children between ages 2 and 6 years who dwell in the temperate zones. Boys and girls are equally affected. The disease arises in bone marrow and is typically marked by pancytopenia, bleeding, fever, bone and joint pain. The leukaemic lymphoblasts are generally monotonous in appearance. They display Ia and common antigens at their surfaces and often are hyperdiploid by cytogenetic analysis and flow cytometry (Look et al., 1982). Mitotic activity is low and thymidine labelling index and percent $S$ phase are usually less than $6 \%$ (Murphy et al., 1977; Look et al., 1982). The course of the disease tends to be relatively slow. Complete remissions are readily induced, remission durations are long and, with conventional combination chemotherapy, the cure rate is in the $60 \%$ range.

Pre-B ALL is a more frequent species in black children with leukaemia than in white (Crist et al., 1984). The cells display cytoplasmic immunoglobulin heavy chains as well as the surface antigens noted in common ALL. A 1:19 chromosomal translocation has been recently identified in 7 of 23 pre-B ALL cases tested (Williams et al., 1984). Duration of remission and cure rate with conventional therapy are less than for common ALL.

Specific cell surface or cytoplasmic markers have not been identified in null ALL (Greaves et al., 1981). Its B-lymphocyte lineage has been identified by gene rearrangement studies (Waldmann \& Korsmeyer, 1983). This species of ALL is more often seen in infants, adolescents and adults (Bowman et al., 1981 b; Greaves et al., 1983). Remission duration and cure rate are less than in common or pre-B (Pullen et al., 1983; Greaves et al., 1981; Pullen et al., 1981; Bowman et al., 1981a).

B-lymphoblastic ALL ('Burkitt-like' cell leukaemia) occurs more frequently in boys than girls and tends to rise from submucosal lymphoid tissue, lymph nodes and viscera (Preud'homme et al., 1981). The cells have a distinct morphology with deep basophilic cytoplasm and cytoplasmic vacuoles and a distinctive $8: 14$ chromosomal translocation. Immunoglobulin is secreted at the cell surfaces. Mitoses are frequent and percent $S$ phase cells are in the $20-25 \%$ range (Look et al., 1982). The disease progresses rapidly with severe metabolic complications. Although remissions are produced by treatment, they are often incomplete and transient. Early mortality is high and survival is poor.

Thymic (T-cell) ALL usually arises in thymic tissue. Patients are more frequently boys, more often older than 6 years and initially tend to have higher peripheral blood values for haemoglobin, granulocytes and platelets than patients with ALL of B-lymphocyte derivation (Greaves et al., 1981). The cells have thymic antigens at their surfaces and often form heat stable rosettes with sheep red blood cells. Pseudodiploidy is often present. An 11:14 chromosomal translocation has been described in 4 of 16 cases examined (Williams et al., 1984). Mitoses are frequent and thymidine labelling index and percent $\mathbf{S}$ phase cells average 12-14\% (Look et al., 1982; Murphy et al., 1977). The disease can progress rapidly with peripheral blood leukaemia cell counts reaching the hundreds of thousands and early development of frank meningeal leukaemia. Metabolic complications are common.

It is popular to use various clinical and laboratory features of patients with ALL to estimate prognosis and to select therapy according to this assessment. The validity of this approach is questionable. First, these prognostic criteria are usually based on complete remission duration rather than cure rate. Since some species of ALL tend to relapse late and other species tend to relapse early, this gives undue weight to biological and clinical features associated with the species in which relapses tend to occur early. For example, thymic ALL tends to relapse within 18 months while non-T non-B ALL continues to relapse over 4 to 5 years (Sallan, 1981). Use of complete remission duration as a criterion for prognosis can exaggerate the importance of thymic species as an unfavourable sign. It also results in exaggeration of the importance of features more often associated with thymic species, such as male sex, older age, mediastinal mass, high initial white blood cell count and norma haemoglobin value in predicting a poor prognosis.

Secondly, methods of prognostic stratification ofter ignore the most important prognostic factor appropriate treatment. Combination chemotherapy results in higher cure rates than single drug treatment and full dosage of drugs is more effective than half dosage. Selection of drugs according to biological species of ALL can also alter outcome. For example, in one comparative study, the long-term leukaemiafree survival rate for children with thymic ALL was the same as for those with non-thymic ALL provided the children with thymic ALL received periodic infusions of cytosine arabinoside and cyclophosphamide (Lauer et al., 1983). Thus the prognostic disadvantage of male sex, older age, mediastinal mass and high initial white blood cell count was overcome in children who received chemotherapy more appropriate to their species of ALL.

It appears that present systems of prognostic stratification of ALL are largely artefacts resulting from our failure to identify biological species of ALL and to treat each accordingly. Our impression, for example, that male sex, mediastinal mass and high white blood cell count are bad prognostic signs and these patients require 'more intensive' therapy is probably incorrect. It is simply that such patients have a distinct biological species of ALL that requires different therapy and that we need to use cure rate and not remission duration as our criterion of success. 


\section{Inducing remission}

There is more agreement about methods of initial induction of complete remission of ALL than perhaps any other features of management. Prednisone, vincristine and asparaginase are the standard combination. Asparaginase appears to be more readily and safely administered by the intramuscular route.

Patients with thymic ALL and B-lymphoblastic ALL are less likely to experience a prompt complete remission than patients with other species (Greaves et al., 1981; Preud'homme et al., 1981). For this reason additional chemotherapy is frequently used. Daunorubicin is often administered as a fourth drug to patients with thymic ALL. Cyclophosphamide, cytosine arabinoside and high dose methotrexate are often included in remission induction chemotherapy for children with B-lymphoblastic ALL (Bowman et al., 1983).

\section{Drug selection by biological species}

It is reasonable to think that the variations in biological properties among species of ALL are reflected by differences in binding, penetration, metabolism and disposition of anti-leukaemia drugs. This would mean that one would achieve more efficacy in therapy by selecting, combining, scheduling and dosing drugs in accordance with the biological species of ALL. To go a step further, it is reasonable to expect that perhaps different approaches to treatment would be appropriate for different biological species.

There is considerable evidence that different chemotherapy should be used for thymic ALL than for non-thymic ALL (Pinkel, 1983b). The most significant clinical data, cited previously, are the results of a study reported by Lauer et al. (1983). They randomized children with ALL in initial complete remission to receive or not receive 3 day courses of cytosine arabinoside (Ara-C) and cyclophosphamide (cyclo) every 8 weeks during remission. All patients received otherwise similar remission induction, meningeal irradiation and continuation chemotherapy. The repeated courses of Ara-C and cyclo had no effect on the leukaemia-free survival of the 150 children with non-T non-B ALL* in the study. For children with thymic ALL results were different. Of 15 children with thymic ALL who received the Ara-C and cyclo courses, only 6 experienced relapse. On the other hand, relapse occurred in 7 of 8 children with thymic ALL who did not receive the Ara-C and cyclo courses. The frequencies of very high initial white blood cell counts and mediastinal masses were similar in both groups.

* The term non-T non-B ALL as used here refers collectively to common, pre-B and null ALL.
These results suggest that children with typical thymic ALL can survive as frequently as children with non-T non-B ALL provided they are given repeated courses of Ara-C and cyclo in addition to the usual therapy. It also suggests that Ara-C and cyclo are specifically useful in thymic ALL and not useful in non-T non-B ALL.

These observations fit well with laboratory data regarding drug specificity of thymic ALL. For example, Ara-C and cyclo are the most effective combinations in the mouse AKR leukaemia, which is a thymic ALL poorly responsive to methotrexate and mercaptopurine (Frei et al., 1974). On the other hand, methotrexate and mercaptopurine are highly effective in mouse L1210 leukaemia, a non-T non-B ALL.

It would seem probable that further experimentation will detect differences in drug sensitivity among the species of ALL derived from the B-lymphocyte lineage. The genetic peculiarities of these different species of ALL suggest that there might be opportunities to exploit specific phenotypic characteristics in designing drug therapy. Whether this will be true or not, it seems reasonable at this point to continue to explore the specific tailoring of anti-leukaemia therapy to fit the several species of ALL of B-lymphocytic lineage as we have for thymic ALL.

\section{Combining drugs for synergism}

The combining of drugs has been a cornerstone of management of ALL. It has not been clear whether the resultant increase in efficacy has represented additive or synergistic effects in all cells, whether the various drugs in the combinations have affected different cells or whether they have affected the same cells at different phases of their life cycles. The benefits of certain drug combinations such as vincristine and prednisone have been abundantly clear without the need for comparative studies. The advantages of many other drug combinations in current use are not proven and in one instance the outcome of a 4 drug combination for continuation therapy of ALL was inferior to that of a 2 drug combination (Aur et al., 1978).

In recent years, laboratory techniques have developed that allow better opportunities for testing drug synergism in patients. High performance liquid chromatography (HPLC) is especially useful for measuring small amounts of drugs in plasma and for assessing nucleotide alterations in cell preparations. The following is an example of applications of these methods in assessing synergy of the combination of methotrexate and cytosine arabinoside in children with ALL.

After several conflicting reports about the synergism of methotrexate and cytosine arabinoside in mouse leukaemias, it was finally determined that the 
agents were synergistic under appropriate conditions (Cadnam \& Eiferman, 1979; Jackson \& Harkrader, 1980). The leukaemia cells had to be sensitive to methotrexate, the methotrexate needed to be administered prior to the cytosine arabinoside and critical levels of both drugs had to be achieved. In vitro chemical studies with L1210 mouse leukaemia cells suggested a rationale for the synergism. When methotrexate-sensitive $\mathrm{L} 1210$ cells were pretreated with methotrexate $>1 \mu \mathrm{M}$ and subsequently exposed to cytosine arabinoside $>1 \mu \mathrm{M}$, intracellular accumulation of cytosine arabinoside was enhanced. At concentrations of methotrexate above $10 \mu \mathrm{M}$, there was also depletion of intracellular deoxycytidine triphosphate (dCTP). The reduction of dCTP was thought to reduce inhibition of deoxycytidine kinase and thus increase phosphorylation of cytosine arabinoside to its metabolically active form, cytosine arabinoside triphosphate. The reduced dCTP would also result in less competition with the cytosine arabinoside triphosphate for DNA polymerase binding, the mechanism of its anti-leukaemia effect.

To test whether achievement of similar sequence and levels of methotrexate and cytosine arabinoside in patients would result in the same cellular nucleotide alterations associated with in vitro synergism in mouse leukaemia cells, we designed the following experiment (Newman et al., 1983). Children in first remission of ALL received a $24 \mathrm{~h}$ infusion of methotrexate, $1 \mathrm{~g} / \mathrm{m}^{2}$. At hour 12 of the methotrexate infusion, a $24 \mathrm{~h}$ infusion of cytosine arabinoside, $1 \mathrm{~g} / \mathrm{m}^{2}$, was initiated. Blood levels of methotrexate and cytosine arabinoside were tested during the infusions. At the end of the cytosine arabinoside infusion, haematopoietic bone marrow was aspirated for determination of intracellular nucleotide levels. Leucovorin 'rescue' was subsequently carried out.

We found in our patients that we could achieve consistent plasma methotrexate levels of approximately $10 \mu \mathrm{M}$ and cytosine arabinoside levels of approximately $1 \mu \mathrm{M}$. The haematopoietic cells demonstrated marked reduction of deoxycytidine triphosphate and high concentrations of cytosine arabinoside triphosphate. Thus the chemical findings in these patients were those associated with drug synergy in vitro. The flaw in the human experiment is that we were testing normal haematopoietic cells and not leukaemia cells. Ethical considerations prevented us from using this drug combination in children with ALL presenting at diagnosis. Nevertheless, the fact that drug sequencing and dosage which result in synergy in vitro can be duplicated in patients and give rise to the same modifications of cellular nucleotides indicates a way toward more precise investigation of drug synergy in vivo in human ALL.

The possible advantage of this drug synergy is being assessed by a current study of the Pediatric Oncology
Group (Krance et al., 1984). Over 50 children with ALL have received intermittent administration of methotrexate and cytosine arabinoside as described above in addition to conventional chemotherapy. Their long-term leukaemia-free survival experience will provide some insight into its efficacy and a basis for comparative study with other drug regimens.

\section{Route of drug administration}

The route by which drugs are administered is based on convenience as well as pharmacological considerations. Mercaptopurine and methotrexate, the basic combination for continuation therapy of non-T non-B ALL have been usually taken orally for the sake of convenience. Their pharmacological effects in patients are apparent from the neutropenia, lymphopenia, macrocytosis of red blood cells and hypersegmentation of neutrophils that usually accompany their oral administration.

However, recent studies indicate that methotrexate absorption from the gastrointestinal tract is variable, that the product of concentration and time of methotrexate is consistently lower with oral administration than with parenteral injection and that red blood cell methotrexate polyglutamate levels are higher in patients receiving intramuscular methotrexate than in those receiving it orally (Balis et al., 1983; Kamen el al., 1984). Since there is correlation between the storage of methotrexate as the polyglutamate and its effectiveness in certain experimental systems, considerable concern has been raised about continued use of methotrexate by mouth. However, at present, there are no comparative data indicating that intramuscular methotrexate is more effective in curing ALL than the oral form. It would seem reasonable to continue monitoring the biological effects of methotrexate on red blood cells and neutrophils while treating children in remission. If red cells are large and neutrophils hypersegmented, it is likely that dosage, absorption and distribution to haematopoietic tissue are adequate, regardless of route of administration.

With regard to mercaptopurine, recent studies have indicated that only a small fraction of the drug reaches the systemic circulation unaltered when given orally (Zimm et al., 1982). However, if granulocyte counts are kept consistently low, it would appear that maximum mercaptopurine effect is being achieved and that perhaps there need not be concern about the fraction absorbed or blood levels achieved.

\section{Intensity and duration of drug administration}

A West German group has expanded the administration of multiple anti-leukaemia drugs in high dosage 
early in remission, a practice dating back to early Leukaemia Study Group B and St Jude studies (Frei $e t$ al., 1965; Aur et al., 1972; Henze et al., 1981). Although toxicity is severe, the West German group reports that the proportion of children remaining in complete remission is higher than with other drug regimens and the unfavourable prognosis associated with thymic ALL is eliminated. The studies have been questioned because they do not compare the intense regimens with more traditional drug therapy. In addition, it is possible that the improved prognosis for thymic ALL is related to the inclusion of cyclophosphamide and cytosine arabinoside in the drug regimen. Since this combination has been shown to be ineffective in extending remissions and increasing cure rate of children with non-T non-B ALL (Lauer et al., 1983), exposing all children with ALL to these drugs in order to benefit the minority with thymic ALL may not be appropriate. It would seem more reasonable to select drugs and drug schedules by biological species of ALL rather than to submit all children to all antileukaemic drugs.

Several lines of evidence suggest that patients with rapidly proliferating ALL should receive shorter and more closely scheduled drug therapy while those with slowly proliferating ALL should receive more prolonged and widely spaced treatment (Pinkel, 1983b).

\section{Preventing meningeal relapse}

Specific meningeal therapy is required to destroy leukaemia cells in the superficial and perivascular arachnoid tissue and thus to prevent meningeal relapse. Several methods have been utilized. The most advantageous appears to be intrathecal administration of methotrexate, cytosine arabinoside and hydrocortisone weekly during remission induction and periodically throughout the first year or two of continuation chemotherapy (Pinkel, 1983b). Triple intrathecal therapy appears to be as effective as methods incorporating irradiation (Sullivan et al., 1982). It avoids the encephalotoxic and carcinogenic effects of irradiation and is more readily available and less expensive than irradiation. Further, children with isolated meningeal relapse have more favourable courses after central nervous system irradiation when they have not been previously irradiated (Nesbit et al., 1982).

Addition of cranial irradiation may be indicated in patients with thymic ALL, particularly those who present with florid disease in their peripheral blood. However, preventive central nervous system irradiation appears to have no value in patients with Blymphoblastic ALL.

\section{Preventing testicular relapse}

Testicular relapse tends to occur late in the course of ALL, often after cessation of chemotherapy (Pinkel, 1983a). Several observations suggest that it is a manifestation of visceral relapse resulting from failure of systemic chemotherapy. At least 3 of the drugs used in ALL diffuse well into the interstitial portion of the testes, where relapse is centered (Forrest et al., 1981; Riccardi et al., 1982). Testicular relapse is often followed shortly by haematological relapse. In one study, laparotomy revealed a high frequency of intraabdominal relapse in boys with clinically isolated testicular relapse (Byrd, 1981).

Testicular biopsy is customarily performed at cessation of chemotherapy. However, some boys with no evidence of testicular leukaemia at cessation of treatment develop frank testicular relapse later on (Askin $e t$ al., 1981). The finding of testicular relapse at any time indicates the need for repeating remission induction chemotherapy and administering an additional 2 to 3 years of continuation chemotherapy, probably incorporating different drugs. Both testes and spermatic cords are usually irradiated as well. Testicular relapse after cessation of chemotherapy has a significant cure rate (Tiedemann et al., 1982).

Prevention of testicular relapse appears to be a matter of improving effectiveness of systemic chemotherapy with regard to selection, dosage and scheduling of drug therapy.

\section{Preventing infections}

Numerous recent publications deal with issues of controlling infection in patients receiving immunosuppressive and haematosuppressive treatment (Pizzo et al., 1984). Prevention is the best method. Most important in prevention is the careful examination of each child prior to and during chemotherapy for sources of infection such as dental abscesses and paronychia. Next is the monitoring of lymphocyte and phagocyte (granulocyte + monocyte) counts, keeping the values for each above $0.7 \times 10^{9} / 1$. The administration of prophylactic cotrimoxazole is effective in preventing Pneumocystis carinii pneumonia. Active immunization of susceptible children with varicellazoster vaccine during remission or passive immunization with varicella-zoster immune globulin shortly after exposure prevents mortality and morbidity from varicella.

Good hygiene and sanitation and minimizing hospital admissions and stays are additional measures worthy of continuous emphasis. 


\section{Bone marrow transplantation}

While bone marrow ablation and transplantation from a compatible sibling are accepted as a standard treatment for acute non-lymphocytic leukaemia, its role in children with ALL is not clearly defined. In one report, 6 of 22 patients with ALL transplanted in 2nd or subsequent remissions remained in remission for over 5 years and were apparently cured (Thomas et al.. 1983). In some centres, patients with ALL in first remission who are expected to have poor outcomes with chemotherapy alone are receiving marrow transplantation. However, sufficient data are not yet published to determine its value relative to chemotherapy alone as primary therapy.

Two points need to be remembered when considering the issue of marrow transplantation in ALL. The main purpose of marrow transplantation is to allow more intensive eradicative treatment of the leukaemia with drugs, irradiation or both. With selection of drugs according to biological species, by utilization of drug synergism and avoidance of drug antagonism. and with appropriate scheduling of drugs according to growth rates, it might be possible to attain antileukaemia effects of the pre-transplant 'conditioning' without need for the transplant itself.

Secondly, children with ALL who experience haematological relapse 6 months or more after cessation of chemotherapy have a good chance of prolonged second remission and possible cure with chemotherapy alone (Rivera. 1981). For this reason, it seems appropriate to confine the use of marrow transplantation to children with ALL who develop haematological relapse while on chemotherapy or within 6 months of its cessation.

Gale and Champlin (1984) compared the relapse rate of patients with acute myelocytic leukaemia who received bone marrow grafts from monozygotic twins to the relapse rate of those who received grafts from HLA-identical siblings. The relapse rate in the twins was three times higher than for the non-twins. The authors suggest that allogeneic bone marrow transplantation might have an immunotherapeutic effect.

Experimental transplantation studies are in progress utilizing autologous marrow treated with monoclonal antibodies directed toward the differentiation antigens characteristic of the patient's ALL (Ritz et al.. 1983).

\section{Immunotherapy}

The use of biological agents to stimulate immune response in children with ALL has been largely abandoned. However, there is considerable interest in the administration of monoclonal antibody preparations directed against differentiation antigens associated with ALL (Levy et al., 1983). Preliminary results indicate that leukaemia cell counts can be decreased and lymphomatous masses reduced by this method, but haematological remissions have not resulted. Obstacles to effectiveness include poor binding of antibody to target cells, blockage of antibodies by free antigen, antigenic modulation, formation of anti-mouse Ig antibodies and lack of effector macrophages.

It is possible that monoclonal antibody therapy might be better tested in patients with ALL in remission who harbour minimal numbers of leukaemia cells. The intent would be to contribute to destruction of residual leukaemia cells while target cells are fewest in number and perhaps therefore more susceptible to serotherapy. The efficacy would be tested by subsequent relapse experience as compared to patients who receive chemotherapy alone.

\section{Psychosocial support}

The basic responsibility of educating the child and his family about leukaemia and its treatment and of helping them to cope constructively with its hardships remains with the physician who treats the child. Social workers, psychologists, child life workers, nurseclinicians and psychiatrists all may have importanto contributions, but they need the guidance and leader ship of the responsible paediatrician in conducting them.

\section{Sequelae}

Quality of survival is a major consideration in the management of children with serious disease. To be truly cured, children not only need to survive the disease, but to retain the capacity for normal growth, development and maturation -- physically, intellectually, emotionally and socially.

In the past, the focus was on immediate and intermediate effects of ALL and its treatment. Visceral and neural leukaemia, gastrointestinal disorders, haematosuppression, immunosuppression, intercurrent infection, bleeding and psychosocial disturbances were major concerns. With many children now surviving off therapy at little risk of relapse, the focus has switched to long-term sequelae.

Physical growth and development have been assessed in survivors. Reduction of linear skeletal increments often occurs during treatment, but after cessation of therapy normal growth patterns usually resume (Verzosa et al., 1976). Some children demonstrate 'catch-up' growth during the first year off treatment.

Normal haematopoiesis and immunological com- 
petence are usually restored by 6 months after cessation of therapy. Many children exhibit a pronounced immunological 'rebound' during the first 3 months of this period (Borella et al., 1972). This normal phenomenon can be confused with haematological relapse.

Endocrinological studies have demonstrated abnormalities of growth hormone secretion after cranial irradiation for ALL (Shalet et al., 1979; Blatt et al. 1984). However, most of these children grow normally once they are removed from chemotherapy. Only a small minority of children demonstrate clinical evidence of growth hormone deficiency. Trials of growth hormone therapy should be reserved for children in complete remission who have been off all chemotherapy for a year or more and have not resumed a normal growth pattern (Romshe et al.. 1984).

Gonadal function has been investigated in children surviving ALL. Blatt et al. (1981) reported normal testicular function in prepubertal and intrapubertal boys. Shalet et al. (1981) concluded that boys with ALL advance through puberty normally, but suggested that many would be oligospermic because of tubular damage by cytotoxic chemotherapy. Prepubertal girls usually progress normally through subsequent puberty and develop normal reproductive ability. Adolescent girls often experience amenorrhoea during chemotherapy, but usually recover ovulatory function after its cessation (Siris et al., 1976). Many survivors of ALL, both male and female, have become parents of healthy children and there is no evidence to date of abnormal incidence of fetal loss or congenital anomalies (Moe et al., 1979; Meadows et al., 1983a).

Neurological and neuropsychological effects of ALL and its treatment have been a major concern. While intracranial leukaemia can leave neurological impairment, irradiation and chemotherapy can produce effects ranging from mild learning disorders to disabling leukoencephalopathy.

Leukoencephalopathy and mineralizing microangiopathy have been attributed to cranial irradiation and subsequent methotrexate therapy (Price \& Birdwell, 1978; Price \& Jamieson, 1975). However, Esseltine et al. (1981) found no differences in the frequency of abnormal computed tomography brain scans between children receiving cranial radiotherapy and those receiving only intrathecal methotrexate.

Distractibility and memory deficits have been reported in children with ALL who received cranial irradiation when less than 8 years old (Goff et al., 1980). In contrast, no global or specific neuropsychological deficits were detected in children with ALL who received intrathecal methotrexate without irradiation (Tamaroff et al., 1982). Jannoun (1983), in the largest study reported, found that children with ALL treated with combination chemotherapy and cranial radiation were functioning within the normal range of intelligence several years after completing treatment. However, children first treated before age 7 years had lower intelligence quotients (IQs) than their normal siblings. Children treated when less than 3 years old had lower IQs than those who were treated when past 3 years of age. Deficiencies in reading and arithmetic were frequent.

Intravenous administration of moderately high doses of methotrexate accompanied by intrathecal methotrexate resulted in abnormal electroencephalograms (EEG) in $68 \%$ of a group of children with ALL (Cohen et al., 1982). One-fifth of the children with abnormal EEGs experienced clinical seizures.

In a current study at St Jude Children's Research Hospital, the effects of moderately high dose intravenous methotrexate are being compared with those of $1800 \mathrm{R}$ of cranial irradiation by serial neurological examination, computed tomography (CT) brain scans, myelin basic protein levels in spinal fluid and neuropsychological evaluation (Ochs et al., 1982). A preliminary report describes a high frequency of seizures in the radiated patients and of abnormal CT scans in the high-dose methotrexate patients. Evidence for neuropsychological dysfunction, EEG abnormalities and myelin basic protein determinations were similar for both groups.

More information is required before we can evaluate conclusively the long-term neurological and neuropsychological sequelae of leukaemia therapy. However, it is legitimate to conclude from reports available that central nervous system irradiation should be avoided whenever possible, especially in preschool children and certainly in infants. Secondly, no more intrathecal therapy should be administered than is demonstrated to be necessary for preventing meningeal relapse. Thirdly, intravenous methotrexate and cytosine arabinoside should be administered cautiously and their frequency and dosage limited to what is found to be necessary for control of systemic leukaemia. Fourthly, the hazards of preventive meningeal therapy are far less than the morbidity and mortality of meningeal relapse. Calculated risks are part of the treatment of children with ALL and in no facet of treatment is this more true than in the prevention of meningeal leukaemia.

Children surviving leukaemia are subject to increased risk of secondary neoplasms (Mosijczuk \& Ruymann, 1981). How much of this risk is related to the child's innate susceptibility to cancer and how much is related to therapy is an unanswered question. One of the future challenges to leukaemia therapists will be to assess the relative carcinogenic risks of the drugs used in leukaemia therapy and to weigh them in the scales against their anti-leukaemia values.

Education, job training and access to health insurance were problems for some of the early survivors of ALL. However, thanks to the more enlightened 
attitudes toward people who are different that mark our era, most children surviving leukaemia are finding few obstacles to their career development, work opportunities and customary social benefits.

\section{Conclusion}

The management of ALL in children is constantly changing as new information and insights accumulate.

\section{References}

ASKIN, F.B., LAND, V.J., SULLIVAN, M.P., RAGAB, A.H., STEUBER, C.P., DYMENT, P.G., TALBERT, J. \& MOORE, T. (1981). Occult testicular leukemia: testicular biopsy at three years continuous complete remission of childhood leukemia. Cancer, 47, 470.

AUR, R.J.A., SIMONE, J.V., VERZOSA, M.S., HUSTU, H.O., BARKER, L.F., PINKEL, D.P., RIVERA, G., DAHL, G.V., WOOD, A. STAGNER, S. \& MASON, C. (1978). Childhood acute lymphocytic leukemia. Study VIII. Cancer, 42, 2123.

AUR, R.J.A., SIMONE, J.V., HUSTU, H.O., \& VERZOSA, M.S. (1972). A comparative study of central nervous system irradiation and intensive chemotherapy early in remission of childhood acute lymphocytic leukemia. Cancer, 29, 381.

BALIS, F.M., SAVITCH, J.L. \& BLEYER, W.A. (1983). Pharmacokinetics of oral methotrexate in children. Cancer Research, 43, 2342.

BLATT, J., BERCU, B.B., GILLIN, J.C., MENDELSON, W.B. \& POPLACK, D.G. (1984). Reduced pulsatile growth hormone secretion in children after therapy for acute lymphoblastic leukemia. Journal of Pediatrics, 104, 182.

BLATT, J., POPLACK, D.G. \& SHERINS, R.J. (1981). Testicular function in boys after chemotherapy for acute lymphoblastic leukemia. New England Journal of Medicine, 304, 1121.

BORELLA, L., GREEN, A.A., \& WEBSTER, R.G. (1972). Immunologic rebound after cessation of long-term chemotherapy in acute leukemia. Blood, 40, 42.

BOWMAN, W.P., BUCHANAN, G.R., \& MURPHY, S.B. (1983). Total therapy B for B-cell acute lymphocytic leukemia (BALL) and stage III-IV B-cell non-Hodgkin lymphoma (BNHL). Proceedings of the American Society of Clinical Oncology, 2, 210.

BOWMAN, W.P., MELVIN, S.L. AUR, R.J.A. \& MAUER, A.M. (1981a). A clinical perspective on cell markers in acute lymphocytic leukemia. Cancer Research, 41, 4794.

BOWMAN, W.P., MELVIN, S.L., KALWINSKY, D.K., DAHL, G.V. \& MAUER, A.M. (1981b). Cell markers in acute lymphocytic leukemia (ALL) patients less than one year of age at diagnosis. Proceedings of the American Association for Cancer Research and American Society of Clinical Oncology, 22, 481.

BYRD, R.L. (1981). Testicular leukemia: incidence and management results. Medical and Pediatric Oncology, 9, 493.

CADMAN E. \& EIFERMAN, F. (1979). Mechanisms of synergistic cell killing when methotrexate precedes cytosine arabinoside: study of L 1210 and human leukemic cells. Journal of Clinical Investigation, 64, 788.

COHEN, M.E., DUFFNER, P.K., BRECHER, M.L., DIAMOND, L.S. GLICKSMAN, A. \& FORMAN, A. (1982). EEGs in disease-free children with acute lymphocytic leukemia
The current degree of success in curing children of ALL should serve as a stimulus to continued research $z$ concerning its pathogenesis and treatment. It is vital $\underset{\mathbb{Q}}{\mathbb{Q}}$ to progress that children with ALL be referred to $c$. leukaemia research centres where they can receive the $\vec{F}$ most up-to-date care and participate in investigations $\stackrel{?}{\rightarrow}$ designed to give them the most benefit at the least risk (Meadows et al., 1983b).

(ALL). Proceedings of the American Society of Clinical Oncology, 1, 135.

CRIST, W., BOYETT, J., ROPER, M., PULLEN, J., METZGAR, R., van EYS, J., RAGAB, A., STARLING, K., VIETTI, T. \& COOPER, M. (1984). Pre-B cell leukemia responds poorly to treatment: a Pediatric Oncology Group study. Blood, 63, 407.

ESSELTINE, D.W., FREEMAN, C.R., CHEVALIER, L.M., SMITH, R., O'GORMAN, A.M., DUBE, J., WHITEHEAD, V.M. \& NOGRADY, M.B. (1981). Computed tomography brain scans in long-term survivors of childhood acute lymphoblastic leukemia. Medical and Pediatric Oncology, 9, 430 .

FORREST, J.D., TURNER, T.T. \& HOWARDS, S.S. (1981). Cyclophosphamide, vincristine and the blood testis barrier. Investigative Urology, 18, 443.

FREI, E. III, SCHABEL, F.M. Jr., \& GOLDIN, A. (1974) Comparative chemotherapy of AKR lymphoma and human hematological neoplasia. Cancer Research, 34, 18

FREI, E. III, KARON, M., LEVIN, R.H., FREIREICH, E.J, TAYLOR, R.J., HANANIAN, J., SELAWRY, O., HOLLAND, J.F., HOOGSTRATEN, B., WOLMAN, I.J., ABIB, E., SAWITSKY, A., LEE, S., MILLS, S.D., BURGERT, E.O. Jr., SPURR, C.L., PATTERSON, R.B., EBAUGH, F.G., JAMES, G.W. III \& MOON, J.H. (1965). The effectiveness of combinations of antileukemic agents in inducing and maintaining remissions in children with acute leukemia. Blood, 26, 642.

GALE, R.P. CHAMPLIN, R.E. (1984). How does bone marrow transplantation cure leukaemia? Lancet, ii, 28.

GEORGE, S.L., AUR, R.J.A., MAUER, A.M. \& SIMONE, J.V. (1979). A reappraisal of the results of stopping therapy in childhood leukemia. New England Journal of Medicine, 300, 269.

GOFF, J.R., ANDERSON, H.R. \& COOPER, P.F. (1980). Distractibility and memory deficits in long-term survivors of acute lymphoblastic leukemia. Developmental and Behavioral Pediatrics, 1, 158.

GREAVES, M.F., DELIA, D., KATZ, F., SCHNEIDER, C., SUTHERLAND, R., \& NEWMAN, R. (1983). Biological diversity of acute lymphoblastic leukemia. In Leukemia Research: Advances in Cell Biology and Treatment, Murphy, S.B. and Gilbert, J.R. (Eds) p. 269. Elsevier Science Publishing Co., Inc.: New York.

GREAVES, M.F., JANOSSY, G., PETO, J. \& KAY, H. (1981). Immunologically defined subclasses of acute lymphoblastic leukemia in children: their relationship to presentation features and prognosis. British Journal of Haematology, 48, 179.

HENZE, G., LANGERMANN, H.-J., RITTER, J., SCHELLONG, 
G. \& RIEHM, H. (1981). Treatment strategy for different risk groups in childhood acute lymphoblastic leukemia: a report from the BFM Study Group. In Haematology and Blood Transfusion 26: Modern Trends in Human Leukemia $I V$, Neth, R., Gallo, R.C., Graf, T., Mannweiler, K. \& Winkler, K. (Eds) p. 87, Springer-Verlag: Berlin/Heidelberg.

JACKSON, R.C. \& HARKRADER, R.J. (1980). Synergistic and antagonistic interactions of methotrexate and 1- $\beta-D$ arabinofuranosylcytosine in hepatoma cells: the modulating effect of purines. Biochemical Pharmacology, 30, 223.

JANNOUN, L. (1983). Are cognitive and educational development affected by age at which prophylactic therapy is given in acute lymphoblastic leukaemia? Archives of Disease in Childhood, 58, 953.

KAMEN, B.A., HOLCENBERG, J.S., TURO, K. \& WHITEHEAD, V.M. (1984). Methotrexate and folate content of erythrocytes in patients receiving oral vs intramuscular therapy with methotrexatc. Journal of Pediatrics, 104, 131.

KRANCE, R., NEWMAN, E., PINKEL, D., ROSEN, R., HARRIS, M., RAVINDRANATH, Y. \& FREEMAN, A. (1984). Intermediate dose methotrexate and Ara-C in continuation therapy of childhood acute lymphocytic leukemia. Proceedings of the American Society of Clinical Oncology, 3, 201.

LAUER, S., CAMITTA, B., SARTAIN, P., BUCHANAN, C., PINKEL, D., KRANCE, R. \& BORELLA, L. (1983). Cytosine arabinoside/cyclophosphamide pulses improve prognosis in childhood T-cell acute lymphocytic leukemia (ALL). Proceedings of the American Society of Clinical Oncology, 2, 77.

LEVY, R., STRATTE, P.T., LINK, M.P., OSEROFF, A., MALONEY, D.G. \& MILLER, R.A. (1983). Monoclonal antibodies in leukemia therapy. In: Leukemia Research: Advances in Cell Biology and Treatment, Murphy, S.B. \& Gilbert, J.R. (Eds), p. 281. Elsevier Science Publishing Co., Inc.: New York.

LOOK, A.T., MELVIN, S.L., WILlIAMS, D.L., BRODEUR, G.M., DAHL, G.V., KALWINSKY, D.K., MURPHY, S.B. \& MAUER, A.M. (1982). Aneuploidy and percentage of Sphase cells determined by flow cytometry correlate with cell phenotype in childhood acute leukemia. Blood, $60,959$.

MEADOWS, A.T., DOMANSKI, L., KRAMER, S., PELTZ, V. \& EVANS, A.E. (1983a). Childhood cancer survivors: Education, employment and reproduction. Proceedings of the American Society of Clinical Oncology, 2, 75.

MEADOWS, A.T., KRAMER, S., HOPSON, R., LUSTBADER, E., JARRETT, P. \& EVANS, A.E. (1983b). Survival in childhood acute lymphocytic leukemia: effect of protocol and place of treatment. Cancer Investigation, 1, 49.

MOE, P.J., LETHINEN, M., WEGELIUS, R., FRIMAN, S., KREUGER, A. \& BERG, A. (1979). Progeny of survivors of acute lymphocytic leukemia. Acta Paediatrica Scandinavica, 68, 301.

MOSIJCZUK, A.D. \& RUYMANN, F.B. (1981). Second malignancy in acute lymphocytic leukemia. American Journal of Diseases in Children, 135, 313.

MURPHY, S.B., AUR, R.J.A., SIMONE, J.V., GEORGE, S. \& MAUER, A.M. (1977). Pretreatment cytokinetic studies in 94 children with acute leukemia, relationship to other variables at diagnosis and to outcome of standard treatment. Blood, 49, 683.

NESBIT, M.E., SATHER, H., ROBISON, L.L., DONALDSON,
M., LITTMAN, P., ORTEGA, J.A. \& HAMMOND, G.D. (1982). Sanctuary therapy: a randomized trial of 724 children with previously untreated acute lymphoblastic leukemia. Cancer Research, 42, 674.

NEWMAN, E.M., TESTI, A.M. \& PINKEL, D. (1983). Biochemical interactions between methotrexate (MTX) and I$\beta$-D-arabinofuranosylcytosine (Ara-C) in patients with acute lymphocytic leukemia (ALL). Proceedings of the American Association for Cancer Research, 23, 107.

OCHS, L., CH'IEN, L., PARVEY, L., BERG, R., WHITAKER. J.. COBURN, T., EVANS, W., CAMPBELL, M. \& BOWMAN, W.P. (1982). Comparison of central nervous system (CNS) toxicity between two methods of CNS prophylaxis $1800 \mathrm{R}$ cranial radiation and moderate dose methotrexate infusion (MDMTX) $1 \mathrm{~g} / \mathrm{m}^{2}$ - in childhood acute lymphocytic leukemia (ALL). Proceedings of the American Society of Clinical Oncology, 1, 75.

PINKEL, D. (1983a). Patterns of failure in acute lymphocytic leukemia. Cancer Treatment Symposia, 2, 259.

PINKEL, D. (1983b). History and development of total therapy for acute lymphocytic leukemia. In Leukemia Research: Advances in Cell Biology and Treatment, Murphy, S.B. \& Gilbert, J.R. (Eds), p. 190. Elsevier Science Publishing Co., Inc.: New York.

PIZZO, P.A., COMMERS, J., COTTON, D., GRESS, J., HATHORN, J., HIEMENZ, J., LONGO, D., MARSHALL, D. \& ROBICHAUD, K.J. (1984). Approaching the controversies in antibacterial management of cancer patients. American Journal of Medicine, 76, 436.

PREUD'HOMME, J.-L., BROUET, J.-C., DANON, F., FLANDRIN, G.M. \& SCHAISON, G. (1981). Acute lymphoblastic leukemia with Burkitt's lymphoma cells: membrane markers and serum immunoglobulin. Journal of the National Cancer Institute, 66, 261.

PRICE, R.A. \& BIRDWELL, D.A. (1978). The central nervous system in childhood leukemia. III. Mineralizing microangiopathy and dystrophic calcification. Cancer, 42, 717.

PRICE, R.A. \& JAMIESON, P.A. (1975). The central nervous system in childhood leukemia. II. Subacute leukoencephalopathy. Cancer, 35, 306.

PULLEN, D.J. For CRIST, W.M., FALETTA, J.M., BOYETT, J.M., ROPER, M., DOWELL, B., van EYS, J., HUMPHREY, G.B., HEAD, D., BORCK, B.L., BLACKSTOCK, R., METZGAR, R.S. \& COOPER, M.D. (1983). A Pediatric Oncology Group classification protocol for acute lymphocytic leukemia (ALinC 13): immunologic phenotypes and correlation with treatment results. In Leukemia Research: Advances in Cell Biology and Treatment, Murphy, S.B. \& Gilbert, J.R., (Eds), p. 97, Elsevier Science Publishing Co., Inc.: New York.

PULLEN, D.J., FALLETTA, J.M., CRIST, W.M., VOGLER, L.B., DOWELL, B., HUMPHREY, G.B., BLACKSTOCK, K.R., van EYS, J., COOPER, M.D., METZGAR, R.S. \& MEYDRECH, E.F. (1981). Southwest Oncology Group experience with immunological phenotyping in acute lymphocytic leukemia of childhood. Cancer Research, 41, 4802.

RICCARDI, R., VIGERSKY, R.A., BARNES, S., BLEYER, W.A. \& POPLACK, D.G. (1982). Methotrexate levels in the interstitial space and seminiferous tubule of rat testis. Cancer Research, 42, 1617.

RITZ, J., SALLAN, S.E., BAST, R.C. Jr., LIPTON, J.M., NATHAN, D.G. \& SCHLOSSMAN, S.F. (1983). In vivo and in vitro use of monoclonal antibodies for treatment of acute 
lymphoblastic leukemia. In: Leukemia Research: Advances in Cell Biology and Treatment, Murphy, S.B. \& Gilbert, J.R. (Eds), p. 97, Elsevier Science Publishing Co., Inc.: New York.

RIVERA, G. (1981). Recurrent childhood lymphocytic leukemia: outcome of marrow relapses after cessation of therapy. In Haematology and Blood Transfusion 26: Modern Trends in Human Leukemia IV, Neth, R., Gallo, R.C., Graf, T., Mannweiler, K. \& Winkler, K. (Eds), p. 94, Springer-Verlag: Berlin/Heidelberg.

ROMSHE, C.A., ZIPF, W.B., MISER, A., MISER, J., SOTOS, J.F. \& NEWTON, W.A. (1984). Evaluation of growth hormone release and human growth hormone treatment in children with cranial irradiation-associated short stature. Journal of Pediatrics, 104, 177.

SALLAN, S.E. (1981). T-cell acute lymphoblastic leukemia in children. Haematology and Blood Transfusion 26: Modern Trends in Human Leukemia IV. Neth, R., Gallo, R.C., Graff, T., Mannweiler, K., Winkler, K. (Eds), p. 121, Springer-Verlag: Berlin/Heidelberg.

SHALET, S.M., HANN, I.M., LENDON, M., MORRIS JONES, P.H. \& BEARDWELL, C.G. (1981). Testicular function after combination chemotherapy in childhood for acute lymphoblastic leukaemia. Archives of Disease in Childhood, 56, 275.

SHALET, S.M., PRICE, D.A., BEARDWELL, C.G., MORRIS JONES, P.H. \& PEARSON, D. (1979). Normal growth despite abnormalities of growth hormone secretion in children treated for acute leukemia. The Journal of Pediatrics, 94, 719.

SIRIS, E.S., LEVENTHAL, GB.G. \& VAITUKAITIS, J.L. (1976). Effects of childhood leukemia and chemotherapy on puberty and reproductive function in girls. New England Journal of Medicine, 294, 1143.

SULLIVAN, M.P., CHEN, T., DYMENT, P.G., HVIZDALA, E. \& STEUBER, C.P. (1982). Equivalence of intrathecal chemotherapy and radiotherapy as central nervous system prophylaxis in children with acute lymphatic leukemia: A Pediatric Oncology Group Study. Blood, 60, 948.

TAMAROFF, M., MILLER, D.R., MURPHY, M.L., SALWEN, R., GHAVIMI, F. \& NIR, Y. (1982). Immediate and longterm post therapy neuropsychologic performance in children with acute lymphoblastic leukemia treated without central nervous system radiation. Journal of Pediatrics, 101, 524.

TIEDEMAN, K., CHESSEllS, J.M. \& SANDLAND, R.M (1982). Isolated testicular relapse in boys with acute lymphoblastic leukaemia: treatment and outcome. British Medical Journal, 285, 1614.

THOMAS, E.D., SANDERS, J.E., FLOURNOY, N., JOHNSON, F.L., BUCKNER, C.D., CLIFT, R.A., FEFER, A., GOODELL, B.W., STORB, R. \& WEIDEL, P.L. (1983). Marrow transplantation for patients with acute lymphoblastic leukemia a long-term follow-up. Blood, 62, 1139.

VERZOSA, M.S., AUR, R.J.A., SIMONE, J.V., HUSTU, H.O. \& PINKEL, D. (1976). Five years after central nervous system irradiation of children with leukemia. International Journal of Radiation Oncology, Biology and Physics, 1, 209.

WALDMANN, T.A. \& KORSMEYER, S. (1983). Hierarchy of immunoglobulin gene rearrangements and deletions in human lymphoid leukemias. In Leukemia Research: Advances in Cell Biology and Treatment, Murphy, S.B. \& Gilbert, J.R. (Eds), p. 77. Elsevier Science Publishing Co., Inc.: New York.

WILLIAMS, D.L., LOOK, A.T., MELVIN, S.L., ROBERSON, P.K., DAHL, G., FLAKE, T. \& STASS, S. (1984). New chromosomal translocations correlate with specific im munophenotypes of childhood acute lymphoblastic leukemia. Cell, 36, 101.

ZIMM, S., NARANG, P.K., RICCARDI, R., O'NEILL, D., CHAT TERJI, D. \& POPLACK, D.G. (1982). The pharmacokinetics of oral (P.O.) 6-mercaptopurine (6-MP). Proceedings of the American Society of Clinical Oncology, 1, 16. 